\title{
New Zealand 2017 Election - The Influence of Voters' Social-Economic Status on the Party Choice
}

\section{Introduction}

A considerable amount of literature has been published about election studies around the world. An area that interests many scholars in those studies is the influence of voters' social-economic status on the party of choice they voted for in elections (Coffe, Voweles \& Curtin, 2014). Therefore, this research intends to identify if the social-economic status of voters influenced their voted choice of party in New Zealand's 2017 election.

It is significant to conduct this study because all political parties present themselves as universal with policies that are beneficial to all citizens (Afnoso, 2016). However, an increasing gap between the rich and the poor should question those policies. It should concern the government, the bureaucrats, and the public because it can affect the social, political, and economic participation of disadvantage groups (Szewczyk, 2015). And because inequality affects all spheres of life, it can influence voters' party choices. The party choice is so significant because it is the party with the majority of candidates that eventually forms the government and which decides on all of the country's affairs which will affect every individual citizen and future generations too.

Because of its significance, much research has been conducted in different countries to identify the influence that voters' social-economic status has on their party choice. For example, Winters et al. (2017) conducted a related study in Britain, Pietsch (2017) in Australia and Suryanarayan (2018) in India and they discovered that there was strong correlation between the social economic status of voters and their party choice. However, a comparable study conducted in the United States by Gelman, Kenworthy and Su (2010) found that there was no clear pattern of relationship between voters' social economic status and their party choice. Gelman et al. (2010) suggest that the influence must be due to other factors such as religion, education, or gender. In New Zealand, Coffe et al. (2014) conducted similar research and found that inequality does affect the party choice of voters and is a significant issue to be addressed. The inequality factors include income inequality, gender inequality, and inequality in the status of other minority groups.

Because gender inequality exists just like income inequality, the probability of gender inequality influencing an election outcome is also high. Coffe et al (2014) explain that it is the support of equality that was widely accepted, giving rise to gender equality rights, income equality rights and the equality and respect for minority groups. Even today, these groups still demand more recognition from the state and the desire of achieving their demands can influence their party choices. Therefore, this research tries to establish the relationship between voters' socialeconomic status and the party they voted for (their party choice) in the 2017 election. Because of the nature of the issue, gender inequality might also influence voters' choices. Gender is used in this study as an interfering variable in the relationship between social-economic status and party-choice.

\section{Research Question}

The main research questions that this literature is centred on are:

i. What is the relationship between voters' social-economic status and their party choice (the party they voted for in 2017 election)?

ii. How does this vary between the genders? 
The first question was designed to establish the relationship (if any) between voters' socialeconomic status and their party choice. Only by establishing the relationship, then the researcher can work out if there is influence of voters social economic status on their party choice, while the second question was to find out if there was gender interference in this relationship.

\section{Hypothesis}

There are several theories (i.e. party identification, social approaches, structural etc...) that can be used to analyse the participants' party choices but one that can best explain how the socialeconomic status of the participants influences their party choices is rational choice theory. Scott (2000) explains rational choice theory as when individuals are motivated to achieve their goals, desires, and interest. Therefore in the context of voting, individual voters will choose the party that best represents their interests. So, applying that theory, it can be generally assumed that citizens with a low social-economic status will vote for left-wing parties (i.e. Labour, and the Green) because these parties' policies favour people of low economic status specifically in terms of wealth redistribution (Coffe et al., 2014). However, people with a higher economic status would oppose that idea and would vote for right-wing parties (i.e. the National, and ACT) to maintain their individual interests. In this research, gender was used as an extraneous variable to see if it has some influence on the relationship between social-economic status and partyvotes. If it does, it will sway the voters with low economic status (low income) to vote for right wing parties, and high economic status (high income) voters to vote for left wing parties as shown in the conceptual framework.

\section{Conceptual Framework}

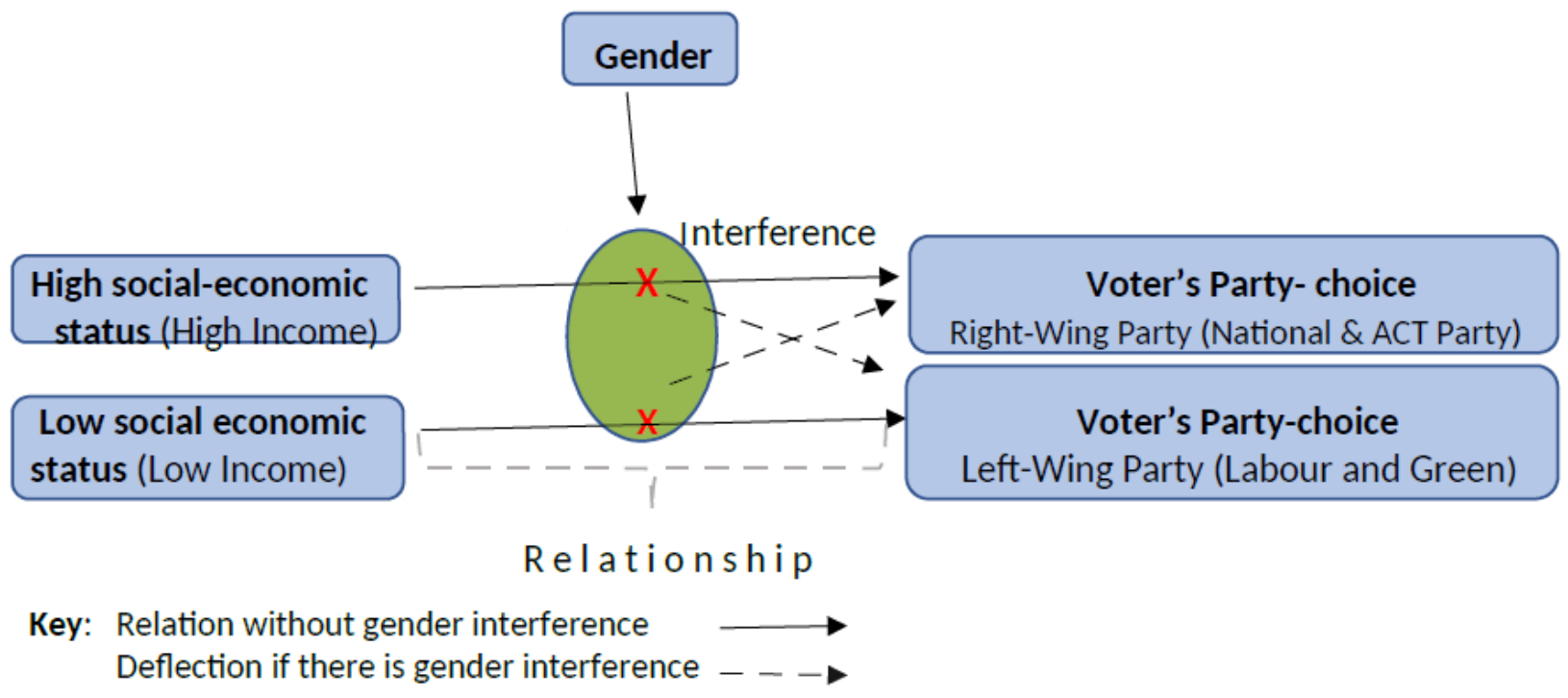

\section{Methodology}

\section{Method of Data Collection}

The data used were from the New Zealand Election Study (NZES) in 2017. NZES data was made available on the students' canvas by the Statistics and Data Analysis for Policy, a course offered by the University of Auckland. The data was collected from a set of self-completion 
questionnaires posted to randomly selected New Zealand registered voters and followed up by phone interviews and online surveys (Vowles, 2018; New Zealand Election Study, n.d).

\section{Data Selection and Processing}

In this study three variables were used: i.e. household income to measure the participants' socialeconomic status, as an independent variable; party vote which reflects voters' party choices, as a dependent variable; and gender as an extraneous variable. These variables were chosen because the main purpose of this study was to establish the relationship between participants' social-economic status and their party-choice and to identify if social-economic status has some influence on the participants' party choice. Gender is only used as an extraneous variable because it might have some influence in this relationship.

For the purpose of data analysis and processing, gender, as a dichotomous variable, was given (1) for male and (2) for female. Social-economic status was measured using the aggregated annual family (household) income by asking the respondents to indicate their income level on the questionnaire, i.e. (0),\$23 800 or less (1), \$23 $801-\$ 35699(2), \$ 35700-\$ 62199$ (3), \$ 62 200 -\$ 76999 (4), \$77 $00-\$ 93599$ (5), \$93 $600-\$ 136599$ (6), \$136 $600-\$ 180199$ (7), \$180 200 or over (8) and don't know (9). Using information provided by the Ministry of Social Development (2018), these different levels of income were categorised into three groups, i.e. low income (no income - \$62,199), medium income $(\$ 62200-\$ 93,599)$ and high income $(\$ 93,600$ and above) as displayed in the results section.

For voters' party-choice, the participants were asked to indicate which party they voted for in the 2017 general election i.e. Labour (1), National (2), Green (3), NZ First (4), ACT (5) Maori Party (6), Mana Party (7), The Opportunity Party (8), Another Party (Other Parties) (10). When processing the data, the respondents who didn't know the political parties they voted for were removed from the analysis and the parties with very low numbers of votes were amalgamated into Other Parties. All these details were entered into SPSS and analysed using RStudio.

\section{Results}

A total of 3,465 people participated in this study. From this sample, $43.5 \%$ ( $n=1507$ ) were males while the other $56.5 \%(n=1958)$ were females. This result shows that there are more female participants in this study.

Graph 1. The Distribution of Participants' Gender

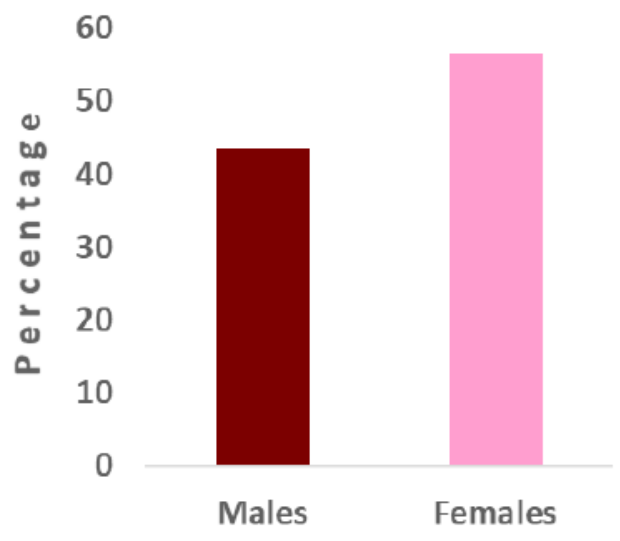

Gender 
In addition, the study showed that most participants voted for the National Party $(39.6 \%, n=1$ 294). The second highest was the Labour Party with $37.6 \%(n=1226)$. The next party after Labour was the Green Party with $8.2 \%(n=268)$, then the NZ First Party with $7.5 \%(n=246)$, The Opportunities Party followed with $3.4 \%$, $(n=110)$, next was the Maori Party with $2.7 \%(n=88)$ and finally the Other parties with $1.2 \%(n=38)$. The information revealed that most of the participants chose the National Party. Even though Labour received fewer votes compared to National, the election was extremely competitive between those two parties. All the other parties were significantly less popular with the voters, with each receiving less than $10 \%$ of the votes.

Table 1 - Distribution of Party-votes

\begin{tabular}{|l|c|c|}
\hline Party & Voter's Receive & Votes in Percentage \\
\hline National & 1294 & 39.6 \\
\hline Labour & 1226 & 37.7 \\
\hline Green & 268 & 8.2 \\
\hline NZ First & 246 & 7.5 \\
\hline The Opportunities Party & 110 & 3.4 \\
\hline Maori Party & 88 & 2.7 \\
\hline Other Party & 38 & 1.2 \\
\hline
\end{tabular}

The research also revealed that most participants were medium income earners $(37.5 \%, n=1119)$ and about $36.5 \%$ ( $n=1075)$ of the participants were high income earners while $26.4 \%(n=786)$ were low income earners. This data means that majority of the voters were from an average economic status. Voters with a high economic status were represented by a significantly high number while those with a low economic status were less represented in this election.

Table 2 - The number of Voters in each Income level

\begin{tabular}{|l|c|c|c|}
\hline Income level & $\begin{array}{c}\text { Number of } \\
\text { Voters }\end{array}$ & Percentage & $\begin{array}{c}\text { Cumulative } \\
\text { Percentage }\end{array}$ \\
\hline Low & 786 & 26.4 & 26.4 \\
\hline Medium & 1119 & 37.5 & 63.9 \\
\hline High & 1075 & 36.1 & 100 \\
\hline
\end{tabular}

The data collected from the study also indicated that there was a low to moderate relationship $(r=0.1191945)$ between the household income and the party. The first relationship shows that party votes for Labour and NZ First increased as the participants' household incomes decreased. A high number of Labour votes were from the low household income group $(43.5 \%, n=316)$, followed by participants with middle incomes $(37.1 \%, n=394)$, and the least party votes were from the high household income earners $(31.3 \%, n=322)$. Just like the Labour Party, the NZ First Party received $3.9 \%(n=40)$ votes from high income earners, 9.2\% $(n=98)$ from medium earners and their highest percentage of votes from low-income earners $(10.3 \%, n=75)$.

On the other hand, the National Party's votes increased as voters' household incomes increased. National's $48.0 \%$ ( $n=494)$ of votes were received from the people with high incomes, $39.0 \%$ $(n=414)$ from medium income-earners and $31.6 \%(n=230)$ from the low income-earners. The 
Green Party and other parties did not show a clear relationship between household incomes-and party votes i.e. the Green's low-income party vote was $8.1 \%(n=59)$, their medium income party vote was $7.2 \%(n=76)$ and their high-income party vote was $9.4 \%(n=97)$. And the low-income vote for the Other Party was $6.5 \%(n=47)$, their medium-income party vote was $7.5 \%$ ( $n=80$ and their high-income vote was $7.4 \%(n=76)$. Even though the Greens and other parties did not have a clear relationship, the general result (including National, NZ First and Labour) showed that there is a positive correlation between household income and party vote which supports our hypothesis that voters with a high social-economic status will vote for a right-wing party (e.g. National) and voters with a low social-economic status will vote for a left-wing party (e.g. Labour).

Table 3 - Distribution of Party-votes by Income level (Group)

\begin{tabular}{|l|c|c|c|c|c|c|}
\hline \multicolumn{1}{|c|}{ Party } & \multicolumn{2}{|c|}{ Low } & \multicolumn{2}{c|}{ Medium } & \multicolumn{2}{c|}{ High } \\
\hline & Frequency & Percentage & Frequency & Percentage & Frequency & Percentage \\
\hline Labour & 316 & 43.5 & 394 & 37.1 & 322 & 31.3 \\
\hline National & 230 & 31.6 & 414 & 39.0 & 494 & 48.0 \\
\hline Green & 59 & 8.1 & 76 & 7.2 & 97 & 9.4 \\
\hline NZ First & 75 & 10.3 & 98 & 9.2 & 40 & 3.9 \\
\hline Other & 47 & 6.5 & 80 & 7.5 & 76 & 7.4 \\
\hline
\end{tabular}

$\mathrm{p}=<0.01, \mathrm{r}=0.1191945-$ meaning that there is a significant low to moderate relationship between Party-votes and Household income

\section{Graph 2 - Graphical representation of the distribution of Party-votes by Income level}

60

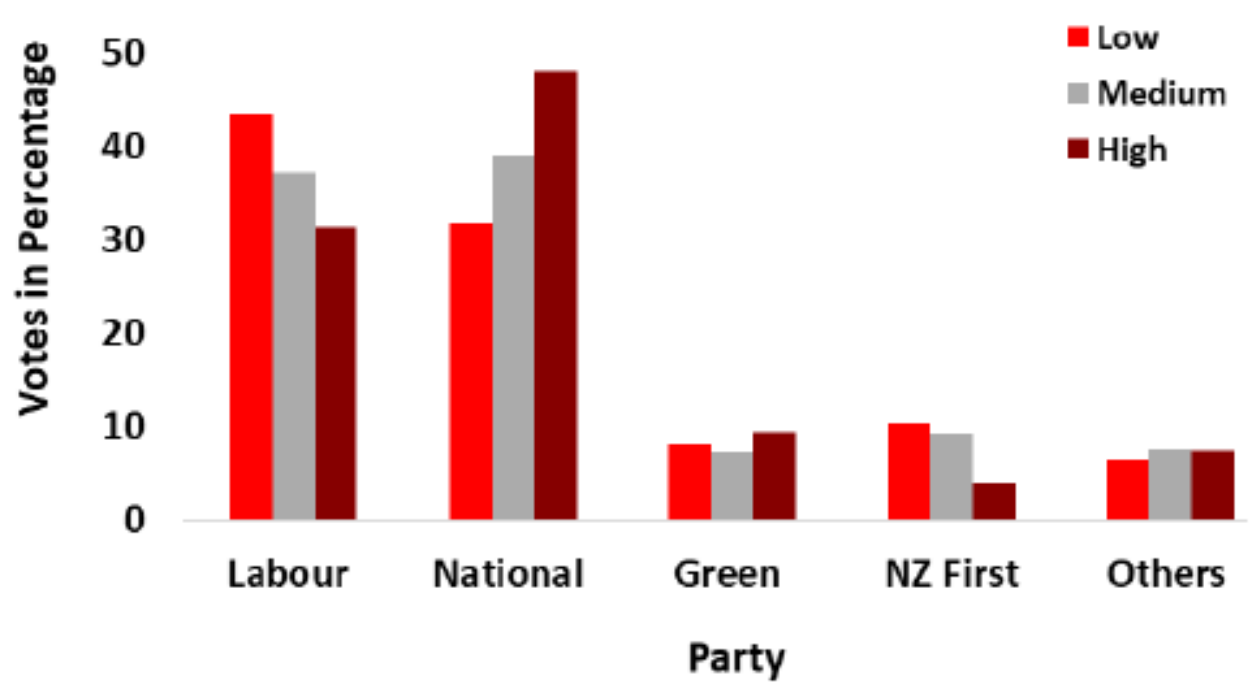

In relation to the gender votes, more females voted for the Labour Party $(41.2 \%, \mathrm{n}=757)$ and the Green Party (8.6\%, $n=159)$ compared to males (Labour: 32.6\%, $n=455$; Green: 7.2, $n=101$ ). On the other hand, most males voted for the National Party $(42.7 \%, n=585)$, the NZ First Party $(9.5 \%$, $\mathrm{n}=133)$ and the Other Parties $(9.0 \%, \mathrm{n}=126)$ when compared to the females i.e. National $38.2 \%$ $(n=702)$, NZ First $6.1 \%(n=112)$ and Other Parties 5.9\% $(n=109)$. This may mean that Labour and 
the Greens (left wing parties) attracted more female voters than the male voters who showed a voting preference for NZ First, National Party and Other Parties.

Table 4 - Distribution of party votes by gender

\begin{tabular}{|l|c|c|c|c|}
\hline \multicolumn{1}{|c|}{ Party } & \multicolumn{2}{c|}{ Male } & \multicolumn{2}{c|}{ Female } \\
\hline & Frequency & Percentage & Frequency & Percentage \\
\hline Labour & 455 & 32.6 & 757 & 41.2 \\
\hline National & 582 & 41.7 & 702 & 38.2 \\
\hline Green & 101 & 7.2 & 159 & 8.6 \\
\hline NZ First & 133 & 9.5 & 112 & 6.1 \\
\hline Other Party & 126 & 9.0 & 109 & 5.9 \\
\hline
\end{tabular}

$p=<0.01 r=0.115088$ meaning that there is a significant low to moderate relationship between the Gender and Party-vote

\section{Graph 3- Graphical representation of the distribution of Party-votes by Gender}

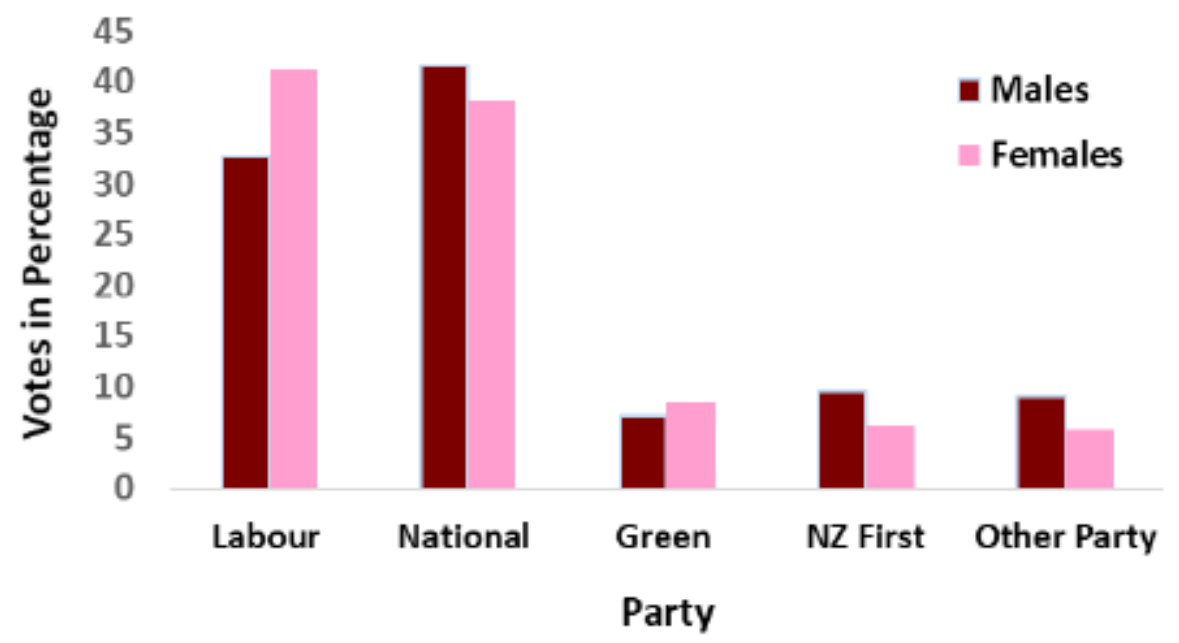

In addition, there were more females with low levels of household income $(22.9 \%, n=476)$ compared to males $(22,7 \%, n=303)$, while there were more males in the medium $(39.1 \%, n=552)$ and the high income levels $(38.2 \%, n=551)$ when compared to the females i.e. Medium level $36.3 \%(n=591)$ and high level $34.5 \%(n=563)$. This means that most females are of lower socialeconomic status compared to most males. 
Table 5 - Distribution of Income by Gender

\begin{tabular}{|l|c|c|c|c|}
\hline Household Income & \multicolumn{2}{|c|}{ Males } & \multicolumn{2}{c|}{ Female } \\
\hline & Frequency & Percentage & Frequency & Percentage \\
\hline Low & 303 & 22.7 & 476 & 29.2 \\
\hline Medium & 522 & 39.1 & 591 & 36.3 \\
\hline High & 511 & 38.2 & 563 & 34.5 \\
\hline
\end{tabular}

$\mathrm{p}=<0.01, \mathrm{r}=0.07397831$ meaning that there is a significant trivial relationship between Gender and the Income level.

\section{Graph 4 - Graphical representation of Income distribution by Gender}

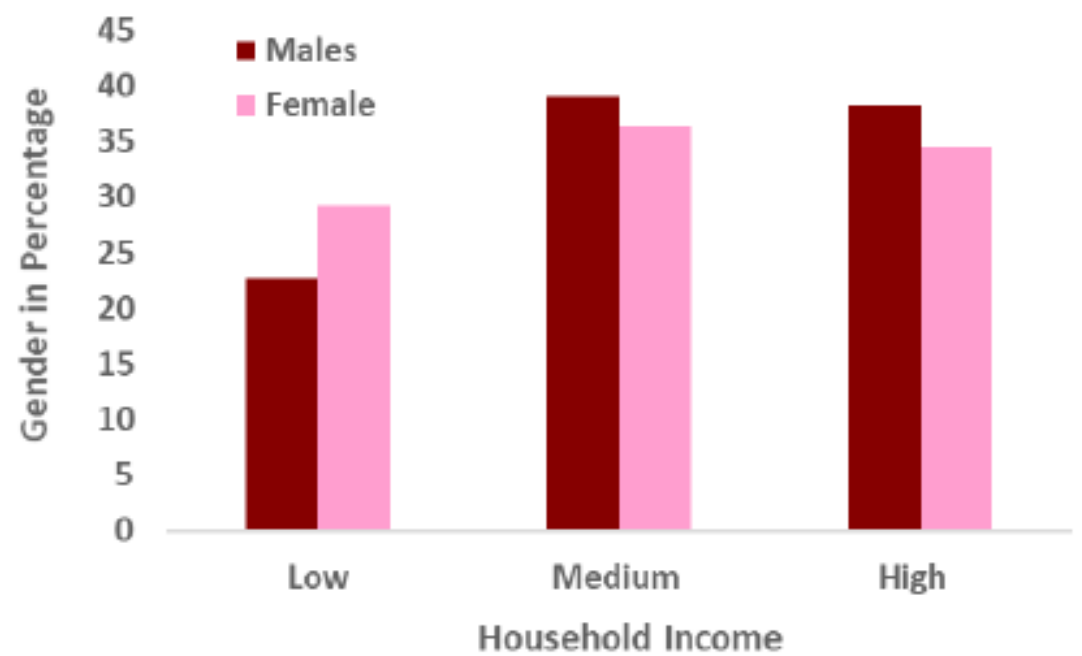

When all variables (income, gender, and party votes) were analysed together, the research revealed that almost equal numbers of males $(42 \%, n=115)$ and females $(43.9 \%, n=196)$ at lowincome levels voted for the Labour Party. However, at the medium income level more females $(42.3 \%, n=239)$ voted for Labour compared to males $(30.9 \%, n=152)$. As with the medium-income earners, more females $(35.9 \%, n=194)$ voted for the Labour Party than males $(26.2 \%, n=128)$ at the high-income level. In contrast to Labour, National received an almost equal number of votes from males $(32.8 \%, \mathrm{n}=87)$ and females $(32.1 \%, \mathrm{n}=143)$ at low-income levels but this increased significantly among the males of medium $(n=40.9 \%, n=201)$ and high-income status $(50.8 \%$, $\mathrm{n}=248)$. Even though National's female vote continued to increase amongst the medium $(37.3 \%$, $n=211)$ and high income $(45.6 \%, n=245)$ earners, it remained low compared to the male vote.

NZ First receive most of its votes from males at all levels of income (i.e. low $13.9 \%, n=38$; medium $11.8 \%, n=58$; high $4.9 \%, n=24$ ) compare to the females (i.e. low $8.3 \%, n=37$; medium $7.1 \%, n=40$; high income $3.0 \%, n=16)$. In addition, the number of its votes decreased as the income level of both genders increased. The Greens' male votes increased as the voters' income levels increased i.e. the vote at low level was $5.1 \%(n=14)$, at medium level it was $7.3 \%(n=36)$ and at high level it was $8.6 \%(n=42)$. The Greens' female vote fluctuated at these levels i.e. low income at $9.6 \%$ $(n=43)$, medium income at $7.1 \%(n=40)$ and high income at $10 \%(n=54)$. The Other Parties 
attracted more male votes at all income levels (i.e. low 7.3\%, $n=20$; medium $9.1 \%, n=45$; high $9.7 \% n=46$ ) than females votes (i.e. low $6.1 \%, n=27$; medium $6.2 \%, n=35$; high $5.6 \% n=30$ ).

These analyses show that most people of low-income status, and females (despite their income status), voted for Labour and the Greens while most people of high-income status, and most males, voted for National. Even though NZ First and Other Parties have their votes evenly spread across different income levels, it is clear that they attracted more male voters than female voters. Therefore, gender may have some influence on voters' party choices because a good number of female high social-economic status voters voted for left-wing parties (opposite to our hypothesis) while a handful of males of high social economic status voted for the left wing Green Party compared to the females. Therefore, the deflection of the voters' choice to the right or to the left (as shown in the conceptual framework) is believed to be caused by gender interference.

Table 6- Distribution of Party-vote by Gender and Income group

\begin{tabular}{|l|c|c|c|c|}
\hline & \multicolumn{2}{|c|}{ Male } & \multicolumn{2}{c|}{ Female } \\
\hline & Frequency & Percentage & Frequency & Percentage \\
\hline Low Earners & & & & \\
\hline Labour & 115 & 42.0 & 196 & 43.9 \\
\hline National & 87 & 31.8 & 143 & 32.1 \\
\hline Green & 14 & 5.1 & 43 & 9.6 \\
\hline NZ Firs & 38 & 13.9 & 37 & 8.3 \\
\hline Others & 20 & 7.3 & 27 & 6.1 \\
\hline Total & 274 & 100 & 446 & 100 \\
\hline Medium Earners & & & & \\
\hline Labour & 152 & 30.9 & 239 & 42.3 \\
\hline National & 201 & 40.9 & 211 & 37.3 \\
\hline Green & 36 & 7.3 & 40 & 7.1 \\
\hline NZ Firs & 58 & 11.8 & 40 & 7.1 \\
\hline Others & 45 & 9.1 & 35 & 6.2 \\
\hline Total & 492 & 100 & 565 & 100 \\
\hline High Earners & & & & \\
\hline Labour & 128 & 26.2 & 194 & 35.9 \\
\hline National & 248 & 50.8 & 246 & 45.6 \\
\hline Green & 42 & 8.6 & 54 & 10.0 \\
\hline NZ Firs & 24 & 4.9 & 16 & 3.0 \\
\hline Others & 46 & 9.7 & 30 & 5.6 \\
\hline Total & 488 & 100 & 540 & 100 \\
\hline
\end{tabular}

\section{Discussion}

This study reveals that there is a significant $(p=<0.01)$ low to moderate correlation $(r=0.1191945)$ between the social economic status (household income) and voters' party choices (party-votes). This means that one variable does exert its influence over the other variable. In the context of this study, it is believed that it was the social-economic status of the voters that influenced the party-choice, demonstrated through their votes. This idea was supported by Afonso, (2016) indicating clearly that people with different levels of income will influence the voting outcome. It can be argued that it is the voters' party choice that influences the voting outcome however Coffe et al. (2014) indicate that income has a high chance of influencing voters' party choices 
because of its direct impact on the voters and is considered as an independent variable compared to the party-vote.

In addition, the study confirms the hypothesis that voters have rational behaviour. This is because the majority of voters with low social economic status $(43.5 \%, n=316)$ voted for the leftwing Labour party which represents their interest of wealth redistribution. On the other hand, the majority of voters with high social-economic status $(48.0 \%, n=494)$ voted for the National party which represents their interest in lowering taxation rates as a mechanism to boost private enterprise. Even though other parties (including the Green Party) might not display a clear relationship, possibly due to the interference of other factors, the relationship between the Labour Party and the National Party was noticeably clear: as income increases, National votes increase (i.e. low, 31.6\%, n=230; medium 39.0\%, $n=414$; and high $48.0 \%, n=494$ ) and as income decreases, Labour votes increase (i.e. high $31.3 \% \mathrm{n}=322$; medium $37.1 \%, \mathrm{n}=394$ and low income $43.5 \%, \mathrm{n}=316)$ as discussed in rational choice theory. NZ First is a centre party that gained most seats from the low-income earners $(10.3 \%, n=75)$, medium $(9,2 \%, n=98)$ and least from high income earners $(3.9 \%, n=40)$. This may be due to its support and its coalition with left-wing parties, specifically Labour party.

Moreover, there was some gender interference in the relationship between social-economic status and party choice. The study shows that even though there is some relationship between social-economic status and party choice, more women prefer left wing parties despite their economic status. For example, the ratio of Labour male to Labour female votes is: i.e. low income 42.0\%: 43.9\%, medium 30:9\%: 43.3\%, high income $26.2 \%: 35.9 \%$. This indicates that Labour not only attracts women voters of low social-economic status, but women of high social-economic status too, whereas most males prefer right wing parties. For example, the ratio of male to female party-votes in National is: low income $31.8 \%$ : $32.1 \%$, medium income $40.9 \%: 37.3 \%$ and high income $50.8 \%: 45.6 \%$. Notably, at low-income levels, there is a higher female to male ratio, but the difference is extremely low. It is not surprising for women to choose the left wing Labour Party because its polices not only favour low income earners but are possibly more favourable to women. It is no coincidence that the Labour Women's Council was formed to assist women in joining the party and to meet the needs of the women across New Zealand's society. That could be a reason for women voting for the Labour Party. This indicates that, even though there is significant correlation between the social-economic status of voters and their party choices, gender also has some influence on this relationship and does interfere with the results by deflecting voters' choices either to left-wing or right-wing parties despite their social-economic status.

\section{Conclusion}

Finally, this study reveals that there is a low to moderate relationship between social-economic status and party choice. It also agrees with the hypothesis that voters are rational beings, therefore the participants with a high economic status voted for right-wing parties while those with a low social-economic status voted for left-wing parties. There was gender interference in this relationship deflecting some of the voters' choices. Therefore, it can be concluded that the social-economic status of citizens did influence the party choice of voters in New Zealand's 2017 election with some gender interference. 


\section{References}

Afonoso, A (2016). To explain voting intentions, income is more important for the Conservatives than for Labour, London School of Economics and Political Science.

https://blogs.Ise.ac.uk/politicsandpolicy/to-explain-voting-intentions-income-is-moreimportant-for-the-conservatives-than-for-labour/

Coffe, H., Vowels, J, \& Curtin, J. (2017). A Bark But No Bite: Inequality and the 2014 New Zealand General election, ANU Press.

Gelman, A., Kenworthy, L., \& Su, Y. (2010). Income Inequality and Partisan Voting in the United States, Social Science Quarterly, 91 (5), 1203 -1219,

Ministry of Social Development. (2018) Household incomes in New Zealand: Trends in indicators of inequality and hardship 1982 to 2017, https://www.msd.govt.nz/about-msd-and-ourwork/publications-resources/monitoring/household-incomes/household-incomes-19822017.html

New Zealand Election Study (n.d). About the New Zealand Election Study - Background on New Zealand Election. http://www.nzes.org/

Pietsch, J. (2017) Trends in migrant and ethnic minority voting in Australia: findings from the Australian election study, Ethnic and Racial Studies, (40)14, 24632480, doi: 10.1080/01419870.2016.1250937

Scott, J. (2000) Rational Choice Theory. In G. Browning, A. Halclic, \& F. Webster (Eds), Understanding Contemporary Society: Theories of the Present (pp 126-138). SAGE Publications Ltd, doi: 10.4135/9781446218310.n9

Suryanarayan, P. (2018). When Do the Poor Vote for the Right Wing and Why: Status Hierarchy and Vote Choice in the Indian States. Comparative Political Studies, 52(2), 209-245, doi. $10.1177 / 0010414018758752$

Szewczyk, J. (2015) The Effects of Income Inequality on Political Participation: A Contextual Analysis, [Honours thesis]. Semantic Scholar https://pdfs.semanticscholar.org/68c8/912e90496e9f3ee626818dd253172d84379a.pdf?_ga=2. $124638031.453043234 .1587626519-2090464412.1555804390$

Vowles, J. (2018) Surprise, surprise: the New Zealand general election of 2017, Kōtuitui: New Zealand Journal of Social Sciences Online, 13 (2), 147-160, doi: 10.1080/1177083X.2018.1443472

Winters, K., Carvalho, E., \& Oliver, T. (2017). The 2015 qualitative election study of Britain. Research Data Journal for the Humanities and Social Sciences, 1(1), p 1-18 doi:10.1163/24523666-01000007 


\section{Appendix - R-codes}

\section{Univariable}

1.1 Gender Distribution (Codes and Information used to produce Graph 1 in the assignment)

$>$ 1ibrary (haven)

$>\operatorname{attach}$ (nzes)

$>$ table(sex)

sex

$\begin{array}{rr}1507 & 2 \\ 1958\end{array}$

$>\operatorname{class}($ sex)

[1] "haven 1abe11ed"

$>$ sexfac<-factor (sex)

$>$ sextab<-table (sexfac)

$>$ sextab

sexfac

$1507 \frac{1}{19} 1958$

$>$ sexptab<-prop. table (sextab) *100

$>$ cbind (sextab, sexptab)

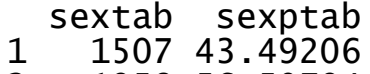

$2 \quad 1958 \quad 56.50794$

$>$ barplot (sexptab,

$+\mathrm{y}$ i $\mathrm{m}=\mathrm{c}(0,60)$,

+ 1as=1, x 1ab="Gender", y $7 a b=" P e r c e n t a g e ", \operatorname{col}=c($ "Brown", "Pink"))

> legend("topleft", c("Ma1e", "Fema1e"), fi 11 =c("Brown", "Pink"))

Graph 1.

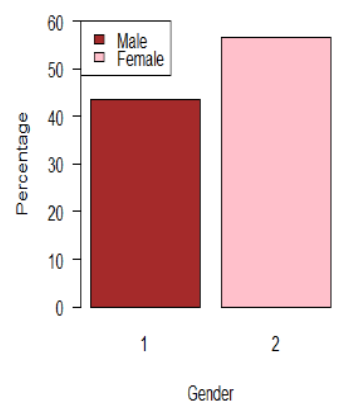

1.2 - Party- Votes (Codes and Information used to produce Table 1 in the assignment)

$>$ 1ibrary(haven)

$>\operatorname{attach}($ nzes )

$>$ table (partyvote)

partyvote

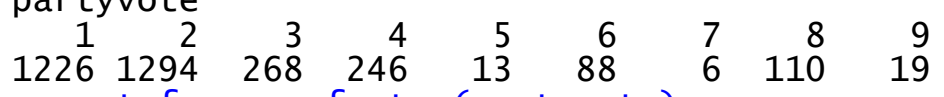

$>$ partyfac<-as factor (partyvote)

$>$ partytab<-table (partyfac)

$>$ partytab

partyfac

Green

Labour

National

268

1226

1294

Māori Party

NZ First ACT

88

24613

Another party

19

$>$ partyptab<-prop.table (partytab)*100 


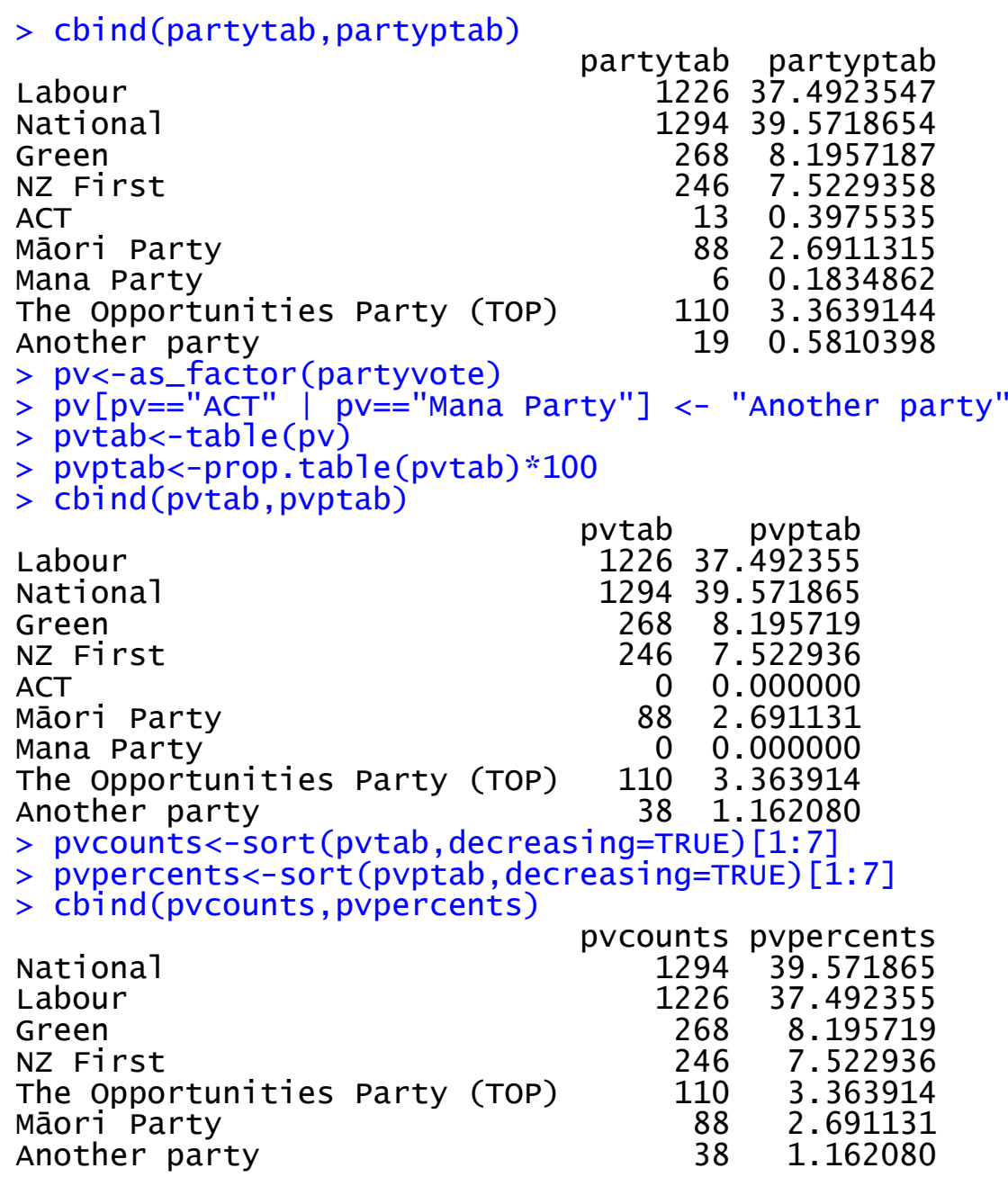

\subsection{Household Income (Codes and Information used to produce Table $\mathbf{2}$ in the assignment)}

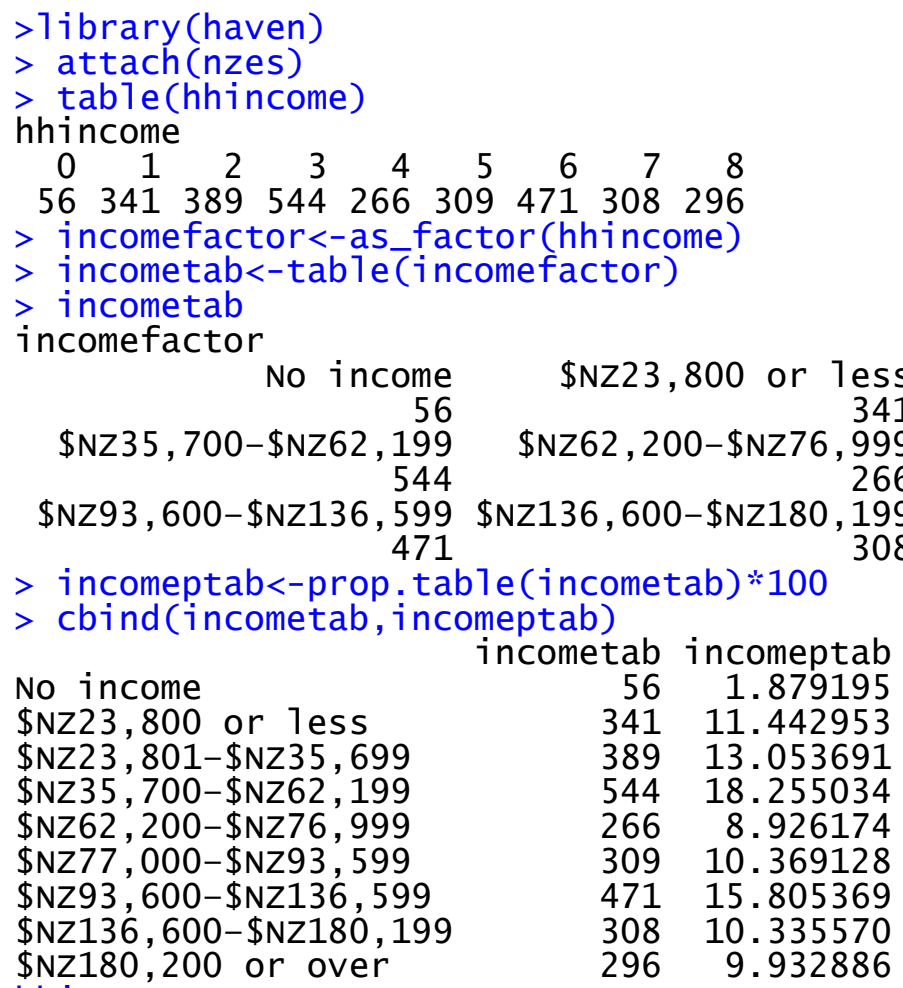

\$NZ23, 801-\$NZ35, 699 \$NZ77, 000-\$NZ93, 599

$\$ N Z 180,200$ or over

hhinc $<-$ NULL

$>$ hhinc $[$ hhincome $<=2]<-1$ 


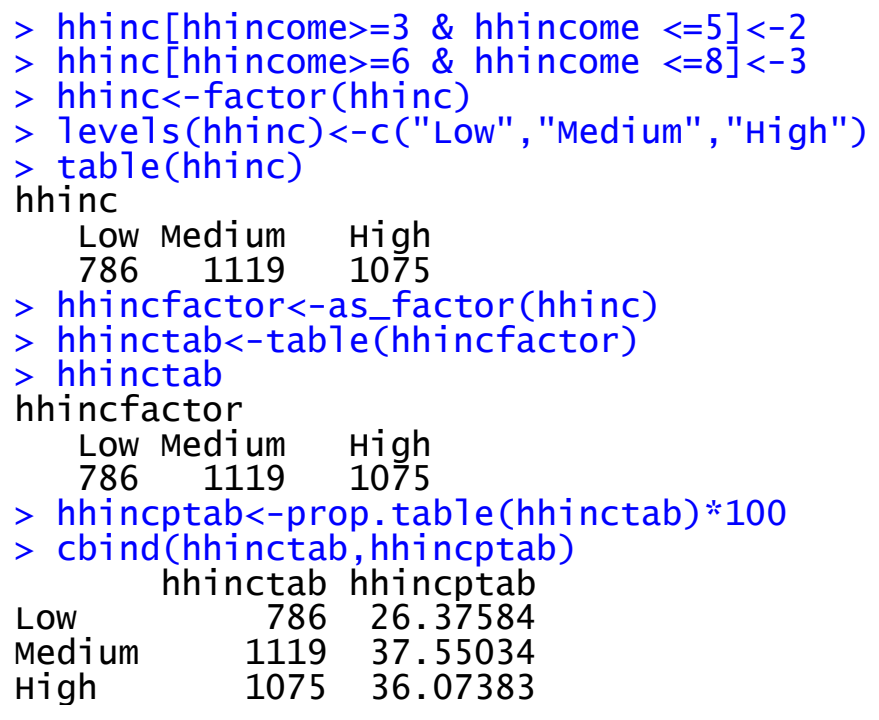

\section{Bivariate}

\section{1 - Household income and Party-votes (Codes and Information used to produce Table 3 and Graph 2 in the assignment)}

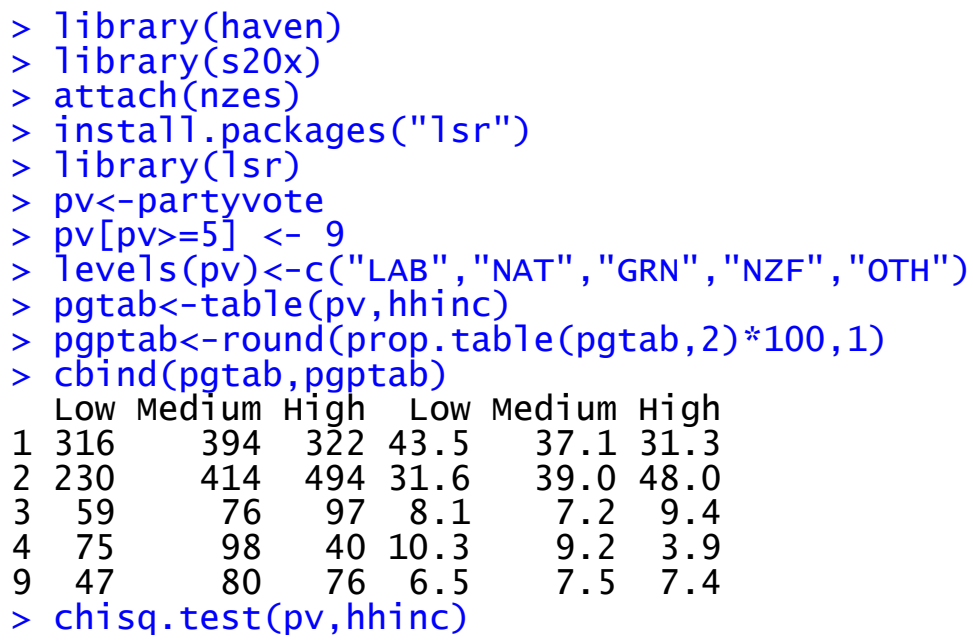

Pearson's chi-squared test

data: pv and hhinc

$\mathrm{X}$-squared $=80.073, \mathrm{df}=8, \mathrm{p}$-value $=4.727 \mathrm{e}-14$

$>\operatorname{cramersv}(\mathrm{pv}$, hhinc)

[1] 0.1191945

+ beside=TRUE, \#put bars next to each other instead of stacking.

$+y \lim =c(0,50)$,

+ 1as=1, x 1ab="party", y 1ab="percentage", col=c("Red", "Grey", "Brown") , font. 1a $\mathrm{b}=2$ )

> legend("topright", c("Low", "Medium", "High") ,fi11=c("Red", "Grey" , "Brown")) 
Graph 2.

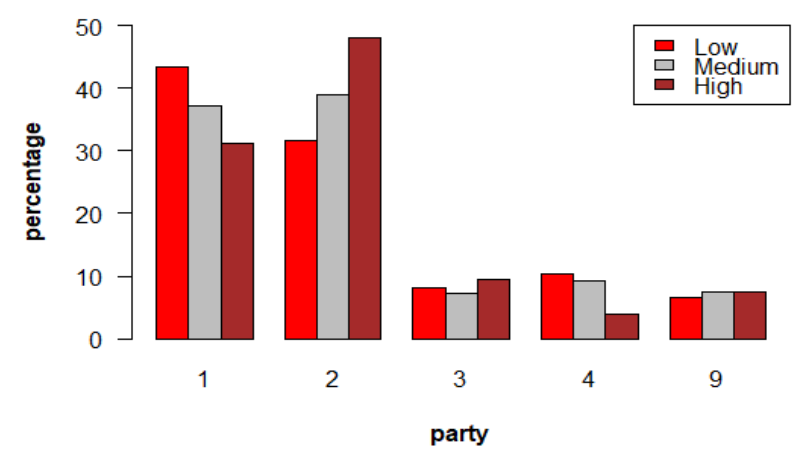

2.2 - Distribution of Party-votes by Gender (Codes and Information used to produce Table 4 and Graph 3)

$>$ 1ibrary(haven)

$>$ 1ibrary (s20x)

$>\operatorname{attach}($ nzes)

$>$ insta11.packages ("1sr")

$>$ 1ibrary(1sr)

$>$ sexfac<-as_factor (sex)

$>$ pv<-partyvote

$>p \vee[p v>=5]<-9$

$>$ pv<-factor $(p v)$

$>$ leve1s (pv) <-c("LAB", "NAT", "GRN", "NZF", "OTH")

$>$ pgtab<-table (pv, sexfac)

$>$ pgptab<-round (prop.table (pgtab, 2)*100,1)

$>$ cbind (pgtab, pgptab)

Male Female Male Female

$\begin{array}{lllll}\text { LAB } & 455 & 757 & 32.6 & 41.2\end{array}$

$\begin{array}{lllll}\text { NAT } & 582 & 702 & 41.7 & 38.2\end{array}$

GRN $101 \quad 159 \quad 7.2 \quad 8.6$

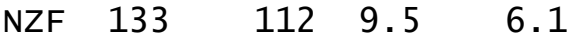

OTH $126 \quad 109 \quad 9.0 \quad 5.9$

$>$ chisq.test (pv, sexfac)

Pearson's chi-squared test

data: $p v$ and sexfac

$\mathrm{X}$-squared $=42.862, \mathrm{df}=4, \mathrm{p}$-value $=1.106 \mathrm{e}-08$

$>\operatorname{cramersv}(p v, \operatorname{sexfac})$

[1] 0.115088

$>$ barplot(t(pgptab), \#transpose is just t().

+ beside=TRUE, \#put bars next to each other instead of stacking.

$+\mathrm{y} 1 \mathrm{im}=\mathrm{c}(0,50)$,

+ 1as=1, x $1 a b="$ party", y $1 \mathrm{ab}=$ "percentage" , col=c ("Red", "Brown"), font. $1 \mathrm{ab}=2$ )

>legend("topright", c("Ma1e","Fema1e"), fi11=c("Brown", "Pink"))

Graph 3

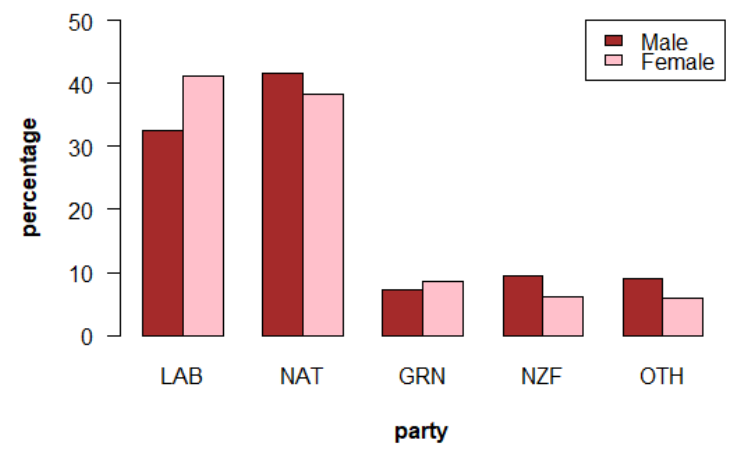




\subsection{Income and Gender Distribution (Codes and Information used to produce Table 5 and Graph 4)}

$>$ 1ibrary (haven)

$>$ 1ibrary (s20x)

$>$ attach (nzes)

$>$ insta11.packages("1sr")

$>$ ibrary(isr)

$>$ sexfac>-as. factor (sex)

$>$ hhinc<-as. factor (hhincome)

$>$ hhinc $[$ hhịncome $<=2]<-1$

$>$ hhinc[hhincome $>=3$ \& hhincome $<=5]<-2$

$>$ hhinc $[$ hhincome $>=6$ \& hhincome $<=8]<-3$

$>$ hhinc $<-$ factor (hhinc)

$>$ leve1s(hhinc)<-c("Low", "Medium", "High")

$>$ table(hhinc)

hhinc

$\begin{array}{lll}\text { Low } & \text { Medium High } \\ 786 & 1119 & 1075\end{array}$

$>$ pgtab<-table(hhinc, sexfac)

$>$ pgptab<-round (prop. table (pgtab, 2)*100,1)

$>$ cbind (pgtab,pgptab)

Male Female Male Female

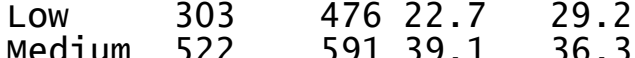

$\begin{array}{lllll}\text { Medium } & 522 & 591 & 39.1 & 36.3 \\ \text { High } & 511 & 563 & 38.2 & 34.5\end{array}$

$>$ chisq. test (hhinc, sexfac)

Pearson's Chi-squared test

data: hhinc and sexfac

X-squared $=16.232, \mathrm{df}=2, \mathrm{p}$-value $=$

0.0002987

$>$ barplot(t(pgptab), \#transpose is just $t()$.

+ beside=TRUE, \#put bars next to each other instead of stacking.

$+\mathrm{y} \lim =\mathrm{c}(0,50)$,

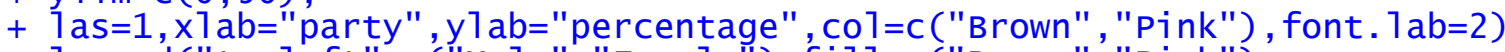

> 1egend("topleft", c("Ma1e"," Fema1e"), fi 11=c("Brown","Pink")

Graph 4.

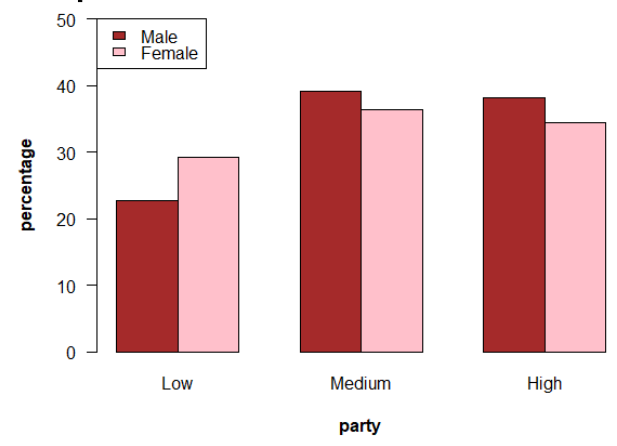

\section{Multivariate}

(Combining all 3 variables in a single table i.e Table 6)

$>$ 1ibrary (haven)

$>1$ ibrary (s20x)

$>\operatorname{attach}($ nzes)

$>$ insta11.packages ("1sr")

$>$ 1ibrary(1sr)

$>$ sexfac<-as_factor(sex)

$>$ pv<-partyvote

$>p \vee[p \vee>=5]<-9$

$>$ pv<-factor (pv)

$>$ 1evels (pv) <-C("LAB", "NAT", "GRN", "NZF", "OTH")

$>$ pgtab<-table (pv, sexfac)

$>$ pgptab<-round (prop.table (pgtab, 2)*100,1) 
$>$ cbind(pgtab,pgptab)

Male Female Male Female

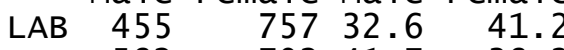

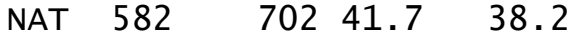

GRN $101 \quad 159 \quad 7.2 \quad 8.6$

$\begin{array}{lllll}\text { NZF } & 133 & 112 & 9.5 & 6.1\end{array}$

OTH $126 \quad 109 \quad 9.0 \quad 5.9$

$>$ pv<-partyvote

$>\operatorname{pv}[\mathrm{pv}>=5]<-9$

$>$ leve1s (pv) <-c("LAB", "NAT", "GRN", "NZF", "OTH")

$>$ pgtab<-table (pv,hhinc)

$>\operatorname{pgptab}<-\operatorname{round}($ prop table $($ pgtab, 2$) * 100,1)$

$>$ cbind(pgtab,pgptab)

Low Medium High Low Medium High

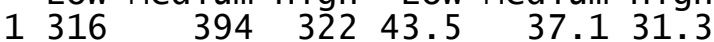

$\begin{array}{lllllll}2 & 230 & 414 & 494 & 31.6 & 39.0 & 48.0\end{array}$

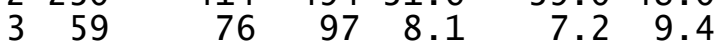

$\begin{array}{lllllll}4 & 75 & 98 & 40 & 10.3 & 9.2 & 3.9\end{array}$

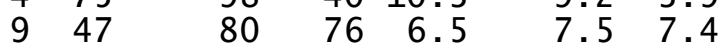

$>$ sexfac<-as_factor (sex)

$>$ pv<-partyvote

$>\operatorname{pv}[\mathrm{pv}>=5]<-9$

$>$ pv<-factor (pv)

$>$ leve1s (pv)<-c("LAB", "NAT", "GRN", "NZF" , "OTH")

$>$ pgtab<-table (pv, sexfac)

$>$ pgptab<-round (prop.table (pgtab, 2)*100,1)

$>$ cbind (pgtab,pgptab)

Male Female Male Female

$\begin{array}{lllll}\text { LAB } & 455 & 757 & 32.6 & 41.2\end{array}$

$\begin{array}{lllll}\text { NAT } & 582 & 702 & 41.7 & 38.2\end{array}$

$\begin{array}{lllll}\text { GRN } & 101 & 159 & 7.2 & 8.6\end{array}$

$\begin{array}{lllll}\text { NZF } & 133 & 112 & 9.5 & 6.1\end{array}$

OTH $126 \quad 109 \quad 9.0 \quad 5.9$

$>$ hhinc $<-$ NULL

$>$ hhinc $[$ hhincome $<=2]<-1$

$>$ hhinc [hhincome $>=3 \&$ hhincome $<=5]<-2$

$>$ hhinc $[$ hhincome $>=6$ \& hhincome $<=8]<-3$

$>$ hhinc<-factor(hhinc)

$>$ Tevels(hhinc)<-c("Low", "Medium", "High")

$>$ pgatab<-table (pv, sexfac, hhinc)

$>$ gatab<-table (pv, sexfac, hhinc)

$>$ pgatab

, , hhinc $=$ Low

\begin{tabular}{lrr}
\multicolumn{3}{c}{ sexfac } \\
pv Male & Female \\
LAB & 115 & 196 \\
NAT & 87 & 143 \\
GRN & 14 & 43 \\
NZF & 38 & 37 \\
OTH & 20 & 27
\end{tabular}

, hhinc $=$ Medium

\begin{tabular}{crr}
\multicolumn{3}{c}{ sexfac } \\
pv & Male & remale \\
LAB & 152 & 239 \\
NAT & 201 & 211 \\
GRN & 36 & 40 \\
NZF & 58 & 40 \\
OTH & 45 & 35
\end{tabular}

, hhinc $=$ High

\begin{tabular}{rrr}
\multicolumn{3}{c}{ sexfac } \\
pv Male & Female \\
LAB & 128 & 194 \\
NAT & 248 & 246 \\
GRN & 42 & 54 \\
NZF & 24 & 16
\end{tabular}




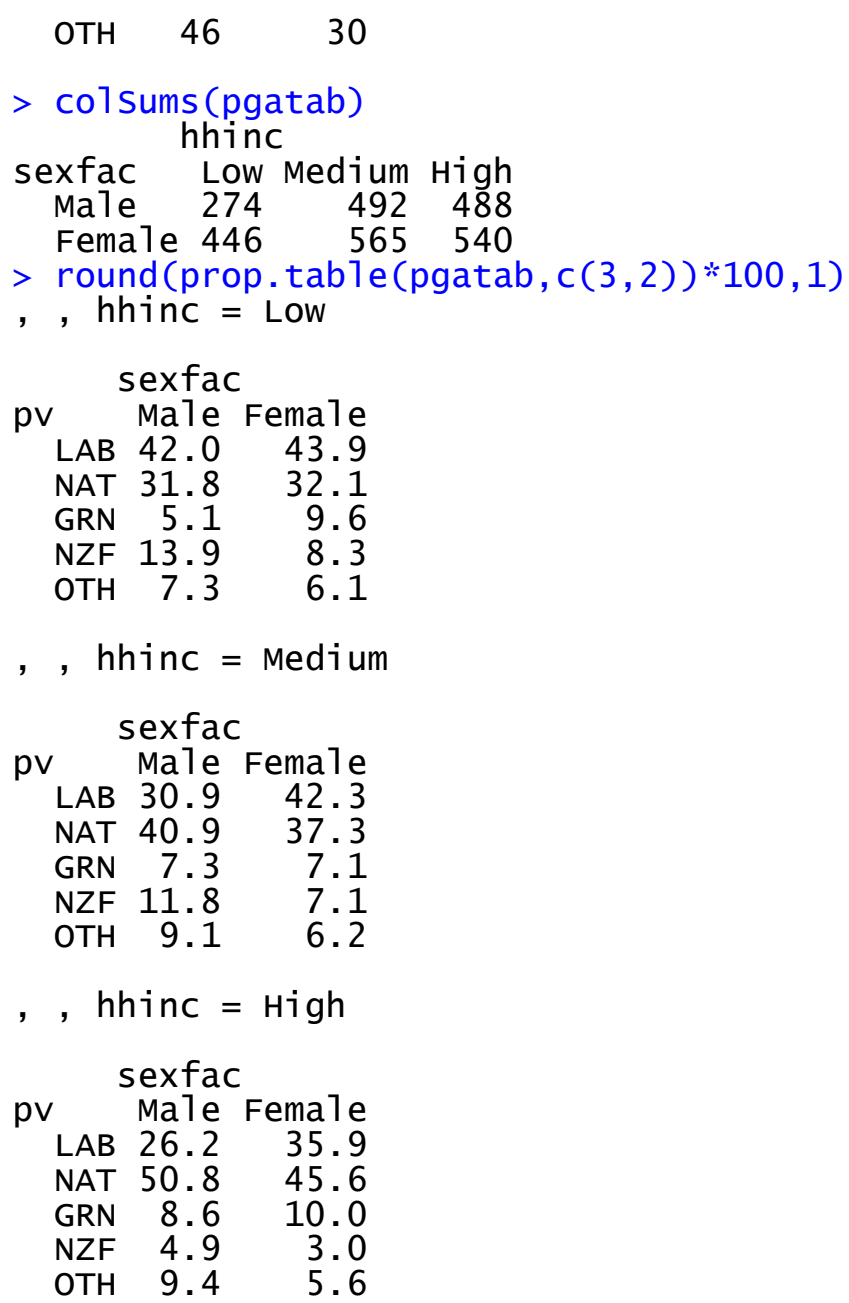

